\title{
Metastatic Breast Neuroendocrine Neoplasm
}

National Cancer Institute

\section{Source}

National Cancer Institute. Metastatic Breast Neuroendocrine Neoplasm. NCI Thesaurus.

Code C156493.

A neuroendocrine neoplasm that arises from the breast and has metastasized to another anatomic site. 